\title{
Hermann Parzinger, Abenteuer Archäologie. Eine Reise durch die Menschheitsgeschichte
}

\section{Eleonore Pape}

\section{OpenEdition}

\section{Journals}

Édition électronique

URL : http://journals.openedition.org/ifha/8805

DOI : $10.4000 /$ ifha. 8805

ISSN : 2198-8943

\section{Éditeur}

IFRA - Institut franco-allemand (sciences historiques et sociales)

\section{Référence électronique}

Eleonore Pape, «Hermann Parzinger, Abenteuer Archäologie. Eine Reise durch die Menschheitsgeschichte », Revue de l'IFHA [En ligne], Date de recension, mis en ligne le 02 novembre 2017, consulté le 24 septembre 2020. URL : http://journals.openedition.org/ifha/8805; DOI : https://doi.org/10.4000/ifha. 8805

Ce document a été généré automatiquement le 24 septembre 2020.

(C)IFHA 


\title{
Hermann Parzinger, Abenteuer Archäologie. Eine Reise durch die Menschheitsgeschichte
}

\author{
Eleonore Pape
}

\section{RÉFÉRENCE}

Hermann Parzinger, Abenteuer Archäologie. Eine Reise durch die Menschheitsgeschichte, M ünchen: C. H. Beck, 2016, 255 p., 19,95€

L'ouvrage de Hermann Parzinger, préhistorien de la steppe eurasiatique, ancien président de l'Institut archéologique allemand (DAI), puis, à partir de 2008, directeur de la Fondation du patrimoine culturel prussien (SPK) à Berlin, présente l'histoire de l'humanité au prisme de l'archéologie. Écrit de façon accessible, avec des sous-titres attrayants et des explications concises de terminologies et de problématiques scientifiques, l'auteur s'adresse prioritairement à des novices et à des personnes s'intéressant à l'archéologie. Son intention de cibler un public large se traduit également par le choix de descriptions vivantes : l'auteur invite à effectuer « une balade à travers des villes romaines » (p. 179) et compare les analyses archéologiques avec des phénomènes sociaux de notre époque contemporaine. Ainsi, les élites du Chalcolithique et de l'âge du Bronze sont comparées aux « magnats de pétroles ou aux managers Gazprom » (p. 85), Néfertiti à une « first lady » (p. 114), ou encore les thermes romaines à nos « salles de fitness avec spas intégrés » (p. 180).

L'ouvrage est divisé en treize chapitres. Le premier présente l'histoire, les méthodes et les objectifs de la discipline scientifique de l'archéologie ainsi que les préjugés qu'on lui associe souvent (par exemple le rapprochement du champ d'action de l'archéologue aux aventures d'Indiana Jones ou à celui des protagonistes du film de Jurassic Park). Les chapitres 2 à 12 traitent de l'histoire de l'homme à partir de l'apparition des hominidés jusqu'à la Seconde Guerre mondiale. Ces derniers suivent la logique du système périodique de Christian Jürgensen Thomson basée sur l'utilisation et les grandes 
innovations matérielles de la pierre, du cuivre, du bronze puis du fer, puis, à partir de la présence de sources écrites, les périodes historiques. Ces chapitres traitent chacun des mouvements migratoires, de la portée d'influences culturelles, des innovations techniques et de leur diffusion, des développements sociaux-culturels ainsi que des interventions de l'homme sur son environnement. Dans le dernier chapitre de l'ouvrage, l'auteur se penche sur le rôle de l'archéologie au sein de notre société actuelle.

$\mathrm{Au}$ fil de l'ouvrage, H. Parzinger présente le panorama des découvertes majeures en archéologie, qui comprennent entre autres les javelots de Schöningen (p. 37), la Vénus de Willendorf en Autriche (p. 54), les immenses agglomérations de la culture de Cucuteni-Tripolje en Ukraine (p. 88), les pyramides de Gizeh (p. 113), les palais mycéniens en Grèce (p. 123), les tombes princières de Hochdorf (p. 147) et du Glauberg (p.155), le champ de bataille de Kalkriese (p. 173), ou encore l'ancienne mairie de Berlin contenant des objets d'art " dégénéré ». Intégrés dans leurs contextes, tous ces objets et toutes ces structures archéologiques servent de témoins neutres du passé dans la mesure où l'archéologue s'efforce de travailler de manière holistique (p. 221, 230). Le texte est accompagné de 71 images et cartes géographiques en couleurs soigneusement choisies, mais elles sont parfois en décalage par rapport au contenu qu'elles illustrent. Cette répartition ne nuit pourtant pas à la compréhension du texte. D'un point de vue scientifique, l'auteur résume la majorité des problématiques et des débats scientifiques actuels de manière critique et neutre à la fois, tout en précisant que le lecteur n'obtiendra pas ici les réponses claires et définitives qu'attend souvent un large public (par exemple p. 45 ou 229).

Directeur de la Stiftung Preußischer Kulturbesitz dont dépendent, entre autres, les Musées d'État de Berlin, H. Parzinger nourrit un intérêt manifeste pour la gestion du patrimoine culturel et la protection des monuments historiques. Il ne cache pas son inquiétude face au commerce illégal d'objets antiques et aux fouilles clandestines (p. 116-117). Quant à la question de la gestion d'objets d'origines étrangères dans les musées occidentaux, H. Parzinger se prononce en faveur d'une responsabilité commune du patrimoine culturel progressivement partagée à travers la mise en place de coopérations internationales égalitaires et de la formation professionnelle de conservateurs de musées dans les pays dits du Sud. Ici, le fait que ces formations et coopérations soient envisagées de façon implicite à partir de critères occidentaux invite cependant à revoir de façon plus articulée et symétrique la valeur d'antiquités au sein de sociétés à travers le monde.

À travers son ouvrage, H. Parzinger donne à ses lecteurs une vue d'ensemble - certes sommaire, mais concise et suffisante à ses fins - sur l'état des connaissances actuelles concernant les développements culturels de nos ancêtres lointains au fil du temps et sur une vaste étendue géographique. Cette tâche est difficile, notamment en raison de la pluralité surprenante des sous-disciplines liées à l'archéologie (la pré- et protohistoire, l'archéologie de l'Antiquité, l'archéologie paléochrétienne et byzantine, l'archéologie des provinces romaines, du Moyen Âge, du Proche Orient, ou l'égyptologie, pour en nommer les principales), auxquelles s'ajoutent en outre les disciplines formant des archéologues experts en sciences dures (l'archéométrie, l'anthropologie physique et biologique, la botanique, la zoologie, la géographie, la géologie, etc.) et en sciences sociales (l'ethnologie, la sociologie, la philologie et l'anthropologie sociale). L'ouvrage présent permet de saisir non seulement la dynamique des évolutions au fil du temps, mais aussi les liens entre les évolutions et les 
phénomènes majeurs de notre histoire. Le fait que l'auteur effectue, dans son écriture, des sauts abrupts dans le temps et l'espace est une problématique incontournable en archéologie, elle exige néanmoins une lecture concentrée et plus approfondie, surtout pour des novices de l'archéologie.

En incluant le passé proche et même le présent dans son odyssée à travers le temps, ce qui est rare, et en plaçant le lecteur au bout de cette longue chaîne de l'évolution culturelle, H. Parzinger parvient à relier le passé et le présent de façon remarquable et à démontrer l'aspect répétitif de phénomènes sociaux et environnementaux (p. 70 par exemple) qu'il caractérise finalement comme étant des constantes. Au vu de l'actualité, notamment des évènements au Proche-Orient évoqués à plusieurs reprises, l'auteur ne manque pas de souligner l'importance de l'archéologie pour la compréhension de l'homme et du monde dans lequel il se situe et appelle au respect mutuel des cultures (p. 13 et 231-232). Avec ce message politique, cet ouvrage s'insère donc lui-même dans une version particulière et humaniste de l'histoire.

INDEX

Thèmes : Histoire de la culture

Index chronologique : Ouvrages transpériodiques

\section{AUTEURS}

\section{ELEONORE PAPE}

Seminar für Ur- und Frühgeschichte, Georg-August-Universität Göttingen 